\title{
Viaje al paraíso perdido: metamorfosis del viaje a Damasco (II)
}

\author{
Ángel Clemente Escobar \\ Universidad Complutense de Madrid \\ angclemen@gmail.com
}

Recibido: 30 de septiembre de 2011

Aceptado: 10 de octubre de 2011

\section{Resumen}

El presente trabajo recupera las transformaciones más relevantes que ha sufrido el imaginario de la ciudad de Damasco en los libros de viaje, con especial atención a los viajeros modernos. Esta imagen, que dependerá de las tradiciones literarias de los sujetos, pero también de las transformaciones históricas y materiales de la ciudad, presenta en principio un modelo de ciudad exótico-oriental, el cual será frecuentemente transgredido a partir de la segunda mitad del siglo XIX. Para completar esta panorámica, en esta segunda entrega recurriremos al comparatismo para identificar los cambios que se producen en la visión que brindan los textos de algunos de los elementos urbanos más significativos de la ciudad ${ }^{1}$.

Palabras clave: literatura de viajes, viajeros, imaginario, Damasco.

Title: Travel to the lost paradise: metamorphosis of travel to Damascus (II) Abstract

This paper brings the most significant transformations undergone by the imagery of the city of Damascus in travel books, paying a special attention to the modern traveler. This image, which relies on the literary traditions of the subjects, but also on the historical and material changes suffered by the city, suggests initially an exotic-oriental city model, which is often transgressed since the second half of the nineteenth century. To complete this picture, in this second part, we resort to comparatism in order to identify the changes produced in some of Damascus' most significant urban elements according to the texts.

Keywords: travel literature, traveller, imagery, Damascus.

\section{Índice}

3. Elementos urbanos para la construcción de la ciudad literaria

3.1. La casa o el hotel: el alojamiento

3.2. Las calles de Damasco

3.3. El templo: la Gran Mezquita de los Omeyas

3.4. Los bazares

3.5. Los baños

3.6. El Vergel del Edén

4. Conclusión

\footnotetext{
${ }^{1}$ La primera parte del artículo se encuentra publicada en Ángulo Recto, vol. 3, núm. 1: http://www.ucm.es/info/angulo/volumen/Volumen03-1/varia07.htm
} 


\section{Elementos urbanos para la construcción de la ciudad literaria}

Muchas ciudades islámicas, como Damasco, que fueron levantadas antes de ser musulmanas, tuvieron que sufrir una profunda transformación, desde el trazado ortogonal característico de la ciudad helena $y$, posteriormente, romana, al que poco a poco se va imponiendo un plano cuya fisonomía se acerca más a la urbe mesopotámica y persa. En sus orígenes, la abundancia de agua favoreció la inserción de esta zona en el trazado de las múltiples vías que unían Mesopotamia al Mediterráneo y Egipto con Anatolia y el mar Egeo. Posteriormente, a la ciudad, que ya había sido capital del Imperio Arameo, la entrada de Grecia con la conquista de Alejandro Magno le reporta un segundo núcleo urbano adyacente, con un trazado regular, además de los elementos urbanos característicos del modelo helenístico como son el ágora y el estadio. Con la llegada de los romanos estas dos áreas son progresivamente unificadas e integradas. La ciudad fue circundada con una sola muralla, de la que hoy quedan algunas partes y las puertas sur y este, y atravesada en el sentido este-oeste por un decumano, la Vía Recta, cuyo trazado hoy es todavía visible.

Con la caída del imperio romano y la posterior pérdida por parte de Bizancio de ciudades como Damasco, que pasan a estar bajo el poder musulmán, se produce una brecha muy importante en la distribución de la cultura urbana entre oriente y occidente. En la Edad Media, cuando las ciudades occidentales eran todavía algo incipiente, las islámicas vivieron su periodo de esplendor. El diseño que surge con la expansión del islamismo presenta una morfología uniforme desde la Península Ibérica hasta la India, yse mantendrá prácticamente sin cambios hasta época moderna (Benevolo 1995: 153), lo cual, en el caso de Damasco, justifica la sensación de la que dejan constancia los primeros viajeros modernos, ya imbuidos en la senda del progreso, que la ven como un lugar donde el tiempo se detuvo hace siglos.

La ciudad islámica se diseñaba en primer lugar para el cumplimiento de los preceptos religiosos, y sus características vienen determinadas sobre todo por la concepción que en materia de relaciones sociales tiene el islam, de signo diferente a Atenas, Roma y Bizancio. La casa es el espacio privado por antonomasia, pero los edificios públicos se reducen con la doctrina coránica: los baños y la mezquita ${ }^{2}$, además del bazar, que es el centro neurálgico de la actividad económica.

\footnotetext{
${ }^{2}$ El porqué nos lo explica Benevolo: "La simplicité du nouveau système culturel, qui est tout entier contenu dans le Coran, produit une réduction des rapports sociaux. C'est pourquoi les villes arabes perdent la complexité des villes hellénistiques et romaines: elles $n^{\prime}$ ont pas forums, de basiliques, de théâtres $[\ldots]$, mais uniquement
} 
La ciudad que nos ocupa presenta, tanto por su configuración como por su antigüedad, un gran número de espacios y escenarios paradigmáticos que el viajero occidental que llega a la ciudad no quiere dejar pasar. Claro está, como en cualquier ámbito, las preferencias cambiarán con el tiempo, y lugares que han sido prácticamente ignorados en otras épocas pueden ser posteriormente puntos de referencia; lo que está condicionado tanto por las circunstancias histórico-materiales de la ciudad como por las de la cultura que a ella se acerca. Vamos a ver algunos de estos espacios recurrentes y su diferente tratamiento por parte de los viajeros de los últimos dos siglos, lo que nos dará una idea más acertada de la evolución reciente que ha sufrido el imaginario creado en torno a la ciudad. Estos espacios serán el templo, el bazar y los baños como lugares públicos de la ciudad, las calles, que dibujan su estructura, y la casa o el hotel, los espacios del descanso y la vida privada del viajero.

\subsection{La casa o el hotel: el alojamiento}

El interior de tu casa es un santuario: los que lo violen llamándote cuando estás en él, faltan al respeto que deben al intérprete de los cielos. Deben esperar a que salgas de allí: la decencia lo exige. (Corán XLIV, vv. 4-5)

Para el viajero, el alojamiento es uno de los puntos clave a la hora de formarse una idea sobre la ciudad que visita. Las posibilidades que se presentaban en Damasco a este respecto han cambiado como es natural enormemente, y las residencias que arrendaban los viajeros que, como Lamartine por ejemplo, llegaban con su séquito, fueron dando paso a los hoteles a finales del siglo XIX. Un siglo después, cuando las características del turismo de masas son la única realidad posible del viaje, son estos establecimientos, los hoteles, los que acaparan prácticamente todos los alojamientos. Ahora, la preservación del color local viene de la mano de los pequeños establecimientos, que el viajero opone a las grandes cadenas hoteleras, con edificios diseñados en un perfecto estilo internacional reconocible en todo el mundo. Dentro de estos últimos, el hotel donde tenía reservada su habitación Rosa Regás para un mes, el hotel Cham Palace, no debía ser de su gusto, porque a la mañana siguiente de su llegada:

Me desperté muy pronto y corrí a la ventana. Diez pisos más abajo y opaca por el cristal ahumado, la calle bullía de animación. Los coches y las gentes se entorpecían unos a otros tratando cada uno de

des habitations privées -maison ou palais- et deux types d'édifices publics: a) les bains pour les besoins du corps; b) les mosquées pour le culte religieux" (Benevolo 1995: 154). 
avanzar, pero en silencio. En un tenue y lejano sonido de fondo descubrí las bocinas apagadas, en sordina, intenté abrir la ventana sin lograrlo, y esa primera visión sin color y sin sonido de Damasco, la ciudad con la que había soñado durante días y noches, me dejó indiferente. Mi habitación, además, tenía ese punto de frescor artificial que parece mantenernos en formol. (Regás 2003: 24)

La vista de los clientes del hotel, los ricos turistas internacionales, que en su mayor parte poco o nada tienen que ver con lo que anda buscando en Damasco, le lleva a la conclusión de que tiene que cambiar de hotel tan pronto como le sea posible.

El vestíbulo, los salones y el comedor estaban llenos de público. Pero poco había que ver. Los ricos del mundo son tan iguales entre sí como los productos de las tiendas de los aeropuertos: hablan el mismo inglés gangoso y estridente, tienen el mismo aire luminoso como si se acabaran de estrenar y se visten de la misma manera: iguales camisetas Benetton y los mismos zapatos Reebok, los chicos; blusas de seda caqui -estamos cerca del desierto- y exagerados pendientes las mujeres, y los caballeros, sean americanos, pakistaníes o colombianos, jóvenes lobos de los negocios o experimentados y sagaces financieros, el mismo corte de traje, el mismo reloj Ebel con pulsera de oro, el mismo perfume a medio camino entre el aroma del tabaco y el jabón de afeitar. ¿Serán los pobres y los humillados los únicos capaces de defender el carácter de sus pueblos? Quizá lo demás a fin de cuentas no sea más que política y folclore. Y mi primer café tenía el sabor amargo, no del cardamomo del café árabe que tanto había de beber después, sino de la inquietud y el desaliento. (Regás 2003: 24)

Aquí la autora opone dos asociaciones bastante tópicas y recurrentes en la literatura de viajes contemporánea: la asociación entre riqueza, esnobismo y desarraigo cultural frente a la de pobreza y tradición.

Un damasceno llamado Fathi, su chófer durante el viaje, será el encargado de informarle de las opciones alternativas en lo que a alojamiento se refiere. La posibilidad de buscar un hotel más modesto queda descartada pues, "-No, no hay hoteles intermedios. O son de lujo, o son simples pensiones un poco destartaladas, y para estar seis semanas no se los aconsejo" (Regás 2003: 25). Entonces, recurriendo a particulares, tal vez existan apartamentos para alquilar para cortos espacios de tiempo o, mejor aún, alguien que alquile habitaciones. En el propio chófer estará la solución, pues éste precisamente tiene una habitación libre que a veces alquila a estudiantes. Así, sin más dilación, recogerá las maletas del que ya era su antiguo hotel y se pondrá rumbo a casa de Fathi y su mujer. Parece que por fin va a conseguir levantarse cada mañana rodeada 
de una imagen que se aproxima mucho más a lo que cree que debe ser un auténtico acercamiento a la ciudad vivida por sus habitantes.

Fathi Alawi y su mujer Nayat vivían en el último piso de una casa de cuatro, en una calle tranquila con acacias en las aceras, paralela a la falda del monte Casiún, sin ascensor -casi ninguna casa lo tiene en Damasco- y un solo piso por rellano. En este barrio, a medio camino entre el residencial de las embajadas y las estribaciones del popular barrio Al Mujayirín así llamado porque en él se refugiaron los emigrantes de la guerra de Argelia, las casas están rodeadas de minúsculos jardines pletóricos de adelfas, mimosas y viñas vírgenes. (Regás 2003: 26)

En el aprendizaje de una ciudad desconocida vemos la importancia del barrio para Regás. Éste es el microcosmos de la ciudad, donde las relaciones entre quienes las habitan y el espacio son más estables, más duraderas, y por lo tanto significativas; todo ello en contraposición al Cham Palace, situado en el centro, lugar de la urbe contemporánea que tiende al desarraigo de quienes lo ocupan, a la despersonalización. Una vez en ella certifica que su nueva habitación, a pesar de estar exenta del lujo y la comodidad de su primer alojamiento, la frialdad que este último le transmitía da paso al calor del carácter local y al ambiente acogedor.

El cuarto no era muy grande pero tenía una inmensa cama de nogal con cuatro colchones delgados y compactos, almohadones, cojín, cabezal y una vánova de algodón blanco adamascado, un armario de luna, una cómoda, una mesa con un ramo de rosas damascenas y dos sillas. La ventana daba sobre los tejados y desde la terracita a la que se accedía por una puerta de persiana verde, se dominaba Damasco y el inmenso llano casi desértico que se extiende hasta Jordania. (Regás 2003: 26)

Al viajero contemporáneo que acostumbrado a ocupar despersonalizados hoteles se le ofrece la oportunidad de convivir con gente del lugar, el hecho se le antoja literalmente como un oasis en medio del desierto. Desde su privilegiada posición intentará captar lo que queda de su imagen exótica en los pequeños detalles. Pero, en cuanto a la vivienda se refiere, ¿cuáles son los ingredientes de ese exotismo? Sin duda, las experiencias y descripciones anteriores, notoriamente las románticas decimonónicas, hacen que el viajero se sienta partícipe del mito por el cual los damascenos, en palabras de Thubron, son los únicos que viven y riegan su propio paraíso, sabiendo que cualquier otro identificaría éste como una búsqueda idealizada de la otredad. En este punto hay que tener en cuenta que el viajero romántico era, por lo general, un individuo con posibilidades económicas para afrontar los gastos que acarreaba una expedición como la que se requería en la época para efectuar un viaje 
por Oriente, lo cual es extensible al alojamiento. El viajero buscará simplemente la casa damascena, concepto que depende más de la imagología que de una realidad arquitectónica en la mayoría de los casos; más ampliamente, el viajero busca encontrar la imagen de lo oriental, también en el lugar donde se aloja.

Uno de los viajeros más espectaculares en medios, Lamartine, fue acogido junto a todo su séquito en una casa propiedad de Mr. Baudin, "agente consular de Francia y de toda Europa", además de agente de la propia Lady Stanhope ${ }^{3}$.

Nous nous arrêtâmes enfin à une petite porte base et étroite, dans une rue où l'on pouvait à peine passer; nous descendîmes du cheval; nous franchîmes un corridor sombre et surbaissé, et nous nous trouvâmes, comme par enchantement, dans une cour pavée de marbre, ombragée de sycomores, rafraîchie par deux fontaines moresques, et entourée de portiques de marbre et de salons richement décorés: nous étions chez M. Baudin. Cette maison est, comme toutes les maisons des chrétiens de Damas, une masure audehors, un palais délicieux au-dedans. (Lamartine 1843: 67)

La casa islámica, incluida por supuesto la damascena, al contrario que la occidental, se abre al interior de sí misma, a su patio, que es el verdadero exterior de la vivienda, aunque colocado en el interior (Benevolo 1995: 154). Además es el lugar donde el ciudadano desarrolla la mayor parte de su vida, bajo el sustento de una idea del hogar y la familia fundada en el sentido de la privacidad y la discreción, que preconiza el Corán, lo que justifica que los viajeros coincidan en señalar la desnudez de las casas al exterior y la importancia del patio en el interior. Muchos de ellos inciden en la idea de que la simplicidad de sus fachadas escondiendo tal vez una fastuosidad interior en las casas damascenas era debido al miedo a los saqueos, lo cual puede ser cierto en el caso de los arameos, pero para el musulmán el recato es sobre todo un signo de respeto para con sus iguales, pues solo Alá es el más grande, hecho que se ve reflejado en el aspecto general de la ciudad (Youssef 1993: 19).

Con los primeros turistas, que hacían el viaje desde Europa en barco hasta Beirut y desde aquí hasta Damasco por carretera -a partir de 1863- o por tren -desde 1895-, aparecen también los primeros alojamientos en la ciudad exclusivamente destinados a acogerlos. Rivadeneyra, por ejemplo, afirma haberse alojado "en la única fonda que hay en la ciudad, cuyo fondista es griego [...]" (2006: 214), aunque, según nos cuenta, cuando estuvo en la ciudad el alquiler de una casa no costaba "más allá de cinco a seis mil reales"

${ }^{3}$ La aristócrata inglesa también se alojó en primera instancia en una casa en el barrio cristiano, pero se trasladó a la zona más noble de la ciudad luego de pedirle al propio Pachá que se la consiguiera. 
(2006: 217). Loti, treinta años después, se aloja en un hotel con el cual, como le sucederá cien años después a Regás, no quedará del todo satisfecho: "un grand hôtel levantin, où le personnel est encore arabe, où il y a encore pas mal de chaux blanche par endroits, mais surtout beaucoup de badigeon, de tableaux et d'ornements atroces" (Loti 2008: 142). Esta aproximación no tiene nada que ver con la descripción de otras casas que visita, más en sintonía con Lamartine que con la óptica del desencanto, como la que realiza de la residencia del pachá Abdullah, cuyo lujo y ornamentación no le parecen precisamente "atroces": "Une porte de forteresse; puis des petits couloirs de casemate, coudés, détournés comme pour être moins pénétrables. Et, tout à coup, des jardins enchantés, entre de fines colonnades de marbre blanc; un éden d'arbres fleuris au milieu d'un décor du vieil Orient merveilleux" (Loti 2008: 149). Más adelante, en el interior, nos cuenta que el pachá le recibió en una sala "digne d'Aladin, composée, suivant la mode damasquine, de deux parties bien distinctes et de niveau différent: la première, celle de l'entrée, ne contenant qu'un jet d'eau dans une grand et superbe vasque de marbre; la seconde, celle du fond [...], meublée de divans et de coussins auxquels cette élévation donne des airs de trône" (Loti 2008: 150).

Podemos afirmar que la moda y la arquitectura que marcarán el estilo en cada momento son también cuestión de dinero y de poder. Todos los viajeros que tienen la oportunidad de visitarlas -los primeros, recordamos, vivieron en ellas- quedan asombrados con el lujo de las residencias de los ricos comerciantes o del propio pachá, como Loti. Ésta última encuentra en el palacio de Assad su equivalente para los viajeros del siglo XX, como Thubron:

El palacio de Assad se repite, a menor escala, en todas las casas antiguas de la ciudad. Desde el exterior, los muros dan una impresión de pobreza que no dejaba entrever nada a los otomanos extorsionistas; las puertas se abren siempre a un pasadizo oscuro, que describe una curva cerrada que impide miradas curiosas. El patio interior nos sorprende de pronto por su sensualidad, con su fuente, que invita a la holganza, poblada de plantas enmacetadas, de la extravagancia del mármol y del aroma de los árboles frutales. En verano, las parras trepan por las paredes y caen desde celosías metálicas en verdes regatas. En otoño, el jazmín y la buganvilla, la adelfa y la verbena recubren las ventanas, y los tiestos se llenan de rosas de Jericó [...]. En algunos casos, las fuentes tienen incrustaciones de pórfido e incluso de nácar. El suelo de mármol, con motivos de vulcanita o arenisca, a veces trepa por las paredes unos cuantos centímetros $\mathrm{y}$, en las casas que conservan totalmente el estilo damasceno, las paredes del patio están rematadas con gruesas bandas de colores vivos, casi siempre. Las ventanas tienen celosías o 
rejas, y unas empinadas escaleras a los dormitorios. (Thubron 2002: 193-194)

\subsection{Las calles de Damasco}

La ciudad islámica distingue dos tipos de calles perfectamente separados, que se relacionan con la zona de la ciudad en que se sitúan y la función que desempeñan (Youseff 1993: 34). El primero de ellos es el de las calles que conforman la medina, cuya estructura gira en torno a la Gran Mezquita, que se situaba en el centro geográfico o simbólico de la ciudad -este es el caso de Damasco-, y adyacente a ésta se extendían el mercado y los edificios públicos como el jan. Son las calles de la ciudad caracterizadas por el ajetreo y el bullicio de la actividad social y económica. Morfológicamente son calles regulares y anchas. El segundo tipo es el formado en los barrios residenciales; estas calles, por su función estrictamente de comunicación, no son zonas habilitadas para la parada. Son calles quebradas y estrechas, con frecuencia sin salida. Es cierto que esto viene motivado por el principio que estructura la ciudad: mientras en occidente la ciudad hace la calle, y esta determina la casa, en la islámica es la casa quien diseña a la calle, y de su adición resulta la ciudad; pero al mismo tiempo es un mensaje de hostilidad hacia los visitantes que se adentran en estos barrios, que tienen la sensación de no poder transitar por ellos con libertad (Youssef 1993: 34). De hecho, jurídicamente las calles que sólo dan acceso a las viviendas tienen un estatus de semi-privacidad.

Existen muchos motivos recurrentes a la hora de describir las calles damascenas. La imagen tópica de la versión canónica de la ciudad se compone de calles estrechas y mal pavimentadas, patrulladas por jaurías de perros; el silencio invade las calles durante todo el día, a excepción de la medina y la llamada a la oración, lo cual encaja perfectamente con el modelo que expone la teoría a este respecto: "La ciudad de Damasco, recorrida a pie, no presenta sino un puro laberinto de callejuelas" nos advierte Rivadeneyra (2006: 216). Además se caracteriza por la proliferación de adarves, calles sin salida que por esta misma circunstancia devienen una no-calle. Sin duda es el granadino ${ }^{4}$ Domingo Arosemena quien nos pinta la imagen más peyorativa de las arterias de la ciudad: "El 17 visitaba las calles inmundas de Damasco. [...] A sus calles angostas e irregulares se une un empedrado malísimo que recorren u ocupan en parte perros asquerosos, que vagan en todas direcciones sin pertenecer á persona alguna" (Arosemena 1859: 56-57).

Ya en el siglo XX, los planes urbanísticos de la ciudad, especialmente el de 1968, crearon nuevas avenidas y espacios que la acercan más al aspecto de las capitales occidentales, que se fueron

\footnotetext{
${ }^{4}$ De Nueva Granada.
} 
fundiendo progresivamente con la ciudad tradicional islámica, y transmitiendo esta última a la primera parte de su carácter. Este es el ejemplo de Regás, que nos transporta a unas calles bulliciosas, con edificios de todos los estilos y épocas y de difícil aprehensión para el viajero:

No lograba ordenar las calles del centro en mi mente. La estación en desuso, los puestos de frutas, las mujeres con niños, la multitud que rodea los hospitales, carritos, el centro de autobuses, soldados, tiendas ambulantes de colonia amarilla o de frutas o de sellos, casas escondidas en jardines umbrosos de adelfas, jazmín y laurel y grandes edificios con palmeras; arquitectura francesa de los años treinta pasada por el gusto árabe, viviendas antiguas con patios cerrados, miradores y balconadas donde el tiempo y el abandono vuelcan la vegetación sobre las rejas e inundan la calle, edificios en construcción, otros a medio derribar. Todo era confusión. (Regás 2003: 44-45)

\subsection{El templo: la Gran Mezquita de los Omeyas}

El templo, como lugar de culto, es considerado un símbolo fundacional de la ciudad (Popeanga 2010: 217), y en el caso de Damasco, la Gran Mezquita lo es en muchos sentidos. Construida entre el 705 y el 715 por el califa Omeya al-Walid, en el emplazamiento de la catedral bizantina de San Juan Bautista, fue la primera mezquita del islam, además de ser uno de los templos continuamente utilizados más antiguos del mundo, pues antes de honrar a San Juan, fue templo romano dedicado a Júpiter y antes aún a Hadad, dios del trueno y de la lluvia en la mitología siria y aramea. Desde su construcción como mezquita ha pasado por tantas manos que apenas queda nada de omeya en ella. Las intervenciones en el edificio han sido motivadas en algunos casos como forma de borrar las huellas de un periodo anterior; pero fundamentalmente estas se produjeron a causa de los desastres que ha sufrido: los incendios de 1069 y 1175 , el saqueo de Tamerlán en 1400, el terremoto de 1759, o el último gran incendio en 1893, son sólo algunas de sus peores fechas.

A través de la poesía podemos saber hoy cuán maravillosos llegaron a ser la totalidad de sus mosaicos, confeccionados por los artesanos traídos de Bizancio. También sabemos de sus transformaciones a través de las crónicas que dieron a conocer los orientalistas durante el siglo XIX, pero su presencia en los libros de viaje es más una cuestión de fe, de riesgo o de deseo -depende del momento- para el viajero occidental, pues fue un espacio vedado a los no-musulmanes hasta después del 1860 (Martín Asuero 2004: 114). Gracias a Ali-Bey, como sabemos disfrazado y convertido al Islam, no hará falta esperar hasta esa fecha para encontrar la 
primera descripción de su interior hecha por un occidental, de la que recogemos algunos fragmentos:

La mezquita principal es magnífica por su extensión; a la entrada se advierte un soberbio castillo de agua, con una fuente, cuyo surtidor se eleva a más de veinte pies. Alrededor de ésta se halla un café, continuamente lleno de gente ociosa.

En el interior de la mezquita hay un gran patio rodeado de galerías y arcos, que descansan sobre columnas y pilares cuadrados. En medio se ve otra fuente con un cenador a cada lado.

Pásese de dicho patio al cuerpo principal de la mezquita, el cual contiene tres inmensas naves en la dirección EO., compuestas de arcos ligeramente puntiagudos, apoyados sobre grandes columnas y pilares. Cuéntanse en cada hilera cuarenta y cuatro columnas, que no son exactamente iguales. Las naves tienen cerca de cuatrocientos pies de longitud.

En medio de la nave del centro, que es la más ancha, hay cuatro enormes pilares sosteniendo una gran cúpula de piedra. Lo restante de la mezquita está cubierto de armadura. [...] A la mitad de la nave del fondo hay un espacio cuadrado y rodeado de celosías, las cuales se abren sólo a la hora de la oración. En aquella especie de presbiterio se hallan el mehereb, el monbar, dos pequeñas tribunas bajas, con grandes coranes para los lectores, y encima el coro para los cantores. [...] Adornan el suelo bellísimas alfombras; y lo restante del pavimento se halla parte desnudo, parte cubierto de alfombras usadas. (Ali-Bey 1982: 435)

Hay que tener en cuenta algo fundamental que se desprende de estos primeros testimonios, y es que la mezquita principal de cualquier ciudad musulmana no es solamente el lugar para la oración y el encuentro con lo religioso, sino que entorno a ella gira la vida intelectual y política de la ciudad, de forma similar a como sucedía en el ágora y el foro, además de estructurar su morfología.

Muchos otros después de Badía no fueron tan atrevidos. George Robinson por ejemplo prefirió no arriesgar: "I did not venture beyond the entrance" (Robinson 1837: 262), pero seducido por lo prohibido, trata de describirnos algo desde fuera:

From whence it appears to be of vast dimensions, and of an imposing effect, [...] It is sex hundred and fifty feet in length, and one hundred and fifty in breadth, and has a large and beautiful marble court, with a tank of water, and granite columns of the Corinthian order, supporting arches, the upper ones being half the height of the lower, and forming a double cloister. During my stay at Damascus, I heard that some Christians, strangers to the town, had been punished (bastinadoed) for merely stopping to look into the court, as I had done. (Robinson 1837: 262) 
Al incidir en su dimensión prohibida y peligrosa, advirtiéndonos que otros han sido castigados por hacer lo mismo que él, el viajero trata de acentuar la componente heroica de su relato, y la anécdota de la mezquita estará presente en las narraciones del viaje hasta su apertura. Lamartine, poco tiempo después, utilizará sus propios recursos para aproximarse a ella y poder contarnos algo: "Il y a péril de mort pour un chrétien qui profanerait les mosquées en y entrant. Nous sommes arrêtés un moment seulement dans le parvis en feignant de nous désaltérer à la fontaine" (Lamartine 1843: 86).

Cuando la situación política se flexibilice en la segunda mitad del siglo XIX, comenzarán a llegar las primeras descripciones occidentales desde Ali-Bey. Estas visitas, que ya no tenían nada de subrepticio, no se producían en todo caso con una absoluta libertad, como nos cuenta por ejemplo Adolfo Rivadeneyra, que tuvo que pedir un permiso especial al bajá e ir acompañado por una escolta. Su mirada ya no estaba interesada en la descripción de los elementos arquitectónicos y ornamentales, los cuales eran ya conocidos por otras fuentes, sino que se centra principalmente en las actividades que los musulmanes desarrollan en el interior: "Por el anchuroso salón, rodeado de un peristilo, se estaban paseando los unos, orando $y$ haciendo contorsiones los otros, algunos durmiendo, yendo $y$ viniendo otros que vendían agua [...]. Entre otras cosas, vi varios sepulcros muy venerados, y muchos niños aprendiendo el Corán" (Rivadeneyra 2006: 215).

Estas descripciones serán muy importantes posteriormente, pues en el último de sus grandes incendios, el de 1893, se perderán una parte del techo, la bóveda de la sala de plegarias y casi todos los mosaicos. Pierre Loti pudo presenciar y testimoniar lo que el fuego había provocado:

Au centre de la ville, gisent les ruines toutes fraîches de la grande mosquée [...] Il y a sept ou huit mois, en plein midi, le feu prit on ne sait comment, dans sa charpente desséchée, et, d'une façon soudaine, en quelques minutes tout flamba comme une pièce d'artifice; puis, dès que la toiture fut effondrée, commença I'anéantissement imprévu de ces colonnes [...]. (Loti 2008: 157)

Es un tópico recurrente también la descripción de los minaretes, desde los cuales por primera vez un almuédano llamó a la oración, imagen que no hace sino alentar las expectativas de vuelta a los orígenes en algún aspecto para los viajeros. A uno de los tres existentes había subido años antes Rivadeneyra, desde donde pudo disfrutar de una panorámica privilegiada de la ciudad. Sin embargo, los avances tecnológicos del siglo XX traerán una visión totalmente renovada de lo que hasta ahora había sido la sobrecogedora experiencia de la llamada a la oración para los viajeros occidentales. 
Es algo que no puede dejar de señalar un viajero tan atento como lo fue Colin Thubron, quien visita Damasco entre 1965 y 1966: "Sin embargo ahora, la llamada a la oración está grabada con voces de almuédanos profesionales de La Meca o El Cairo, y los altavoces se asoman sin rubor a la calle desde los muros de la mitad de las mezquitas de la ciudad" (Thubron 2002: 121-122). En su visita al interior pudo comprobar cómo, más de setenta años después del incendio, aún continua una reconstrucción que parece no tener fin: "En la mezquita se trabaja constantemente. Los artesanos del mosaico cubren el muro del crucero con diseños reconstruidos de los restos del siglo XVIII del pórtico occidental. [...] Pregunté cuánto tardarían en volver a cubrir toda la mezquita como antes, pero nadie lo sabía" (Thubron 2002: 122).

A partir de los años sesenta, con la masificación del turismo se producirá un cambio en la forma de acceso a los lugares sagrados como la Gran Mezquita, los cuales serán específicamente preparados para la recepción de turistas. Por un lado, esto otorga la posibilidad a todos sus visitantes de disfrutar del espacio, al cual acceden de una manera planificada, conducida. Es así como el encanto del que anteriormente había sido un lugar sagrado para algunos y un espacio prohibido para otros, se vulgariza para los primeros y es percibido como una banalización del espacio sagrado para los musulmanes.

Pasamos la puerta lateral de la mezquita reservada para los extranjeros y entramos por la puerta norte, junto al mausoleo de Saladino - de 1193, leyó Ralph en la guía- en medio de un umbroso jardín y contemplamos junto a él la tumba moderna, en mármol que, añadió, el emperador Guillermo II regaló al pueblo de Damasco durante su visita en 1898.

Nos pusimos un manto negro, Ralph porque llevaba pantalones cortos, yo sólo por ser mujer.

Atravesamos el inmenso atrio porticado donde paseaban grupos de hombres y mujeres junto a la fuente de las abluciones. Nos acercamos a la cúpula del tesoro donde antiguamente se guardaba el dinero público, decorada con mosaicos. Y al entrar en el 'haram', la sala de la plegaria, nos quitamos los zapatos y los dejamos en el suelo junto a los de los visitantes y oradores. (Regás 2003: 49-50)

El espacio religioso queda así transformado e incluido como parte de un tour turístico delimitado, por el cual los turistas transitan provistos de su guía y dispuestos a no dejar pasar ninguno de los elementos que en ella se enumeran. Las pocas posibilidades que éstos tienen de interactuar con el lugar que visitan y sus moradores habituales hacen que esta experiencia del espacio sagrado sea percibida más como un simulacro que como una forma de acercamiento real religioso. Lejos están este tipo de viajeros de otros como Ali-Bey, quien hubo de mostrar un profundo conocimiento del 
islam y una importante preparación antes de aventurarse a entrar en el recinto.

\subsection{Los bazares}

En la ciudad musulmana generalmente la vida pública gira en torno a los bazares. En Damasco han sido objeto de especial observación por parte de los viajeros, al posibilitarles por sus características una mirada sobre las relaciones, no sólo comerciales, sino también sociales y políticas de los damascenos. De nuevo, las descripciones que aportan más datos son las llevadas a cabo por Domingo Badía, dando cuenta de tiendas atestadas de géneros textiles, los comercios de los guarnicioneros, la industria del acero, los carpinteros, herreros, jaboneros, la arquitectura de sus recintos o los servicios y alimentos que en ellos se pueden encontrar. Pero si hay una mercancía que para el barcelonés merece especial alabanza es precisamente esta última:

Los mercados de comestibles igualan y aun exceden en abundancia a los bazares destinados a la venta de los otros géneros. Los que se venden son de superior calidad, y no creo que haya en el mundo país donde los víveres sean mejores: hállanse carnes substanciosas y delicadas, legumbres y verduras muy tiernas; frutas suculentas, dulces, y de monstruoso tamaño; caza abundante de toda especie; miel y lacticinios deliciosos; pan más blanco y mejor que en Europa; en una palabra, puede asegurarse es el mejor sitio del mundo para la vida animal. (Ali-Bey 1982: 438)

La riqueza de los frutos es otro de los ingredientes recurrentes a la hora de caracterizar el espacio exótico, y en el caso de Damasco se relaciona además con el tema del vergel y su condición de paraíso terrenal, del cual hablaremos después.

Para el viajero romántico la enumeración de multitud de objetos y mercancías, tanto autóctonos como procedentes de lugares remotos, era otra forma más de acentuar el exotismo en sus relatos. Las alfombras, la seda o las piedras preciosas encajaban perfectamente con la imagen de sensualidad y belleza que se pretendía transmitir, en lo que se conjuga como un imaginario que podríamos denominar del "lujo oriental". Los comestibles, las especias en particular, son destacados también por señalar la oposición con la gastronomía propia. El viajero busca comprar objetos que sirvan como testimonio de su hazaña, y esto ocurre en cualquier época. Pero al viajero romántico no le vale con cualquier cosa, y buscará entre la gran variedad de mercancías la que más se ajuste a unas expectativas tan superlativas como las que su viaje promete. Este es el caso de Lamartine, quien invadido por un espíritu aventurero decide comprar un caballo blanco de tres años, "la perle 
de tous les chevaux du désert" (Lamartine 1843: 78), además de cuatro baúles.

Durante todo el siglo XIX los viajeros describen el bazar como el único espacio de la ciudad donde reinan el bullicio y la agitación, en contraste con el silencio y la quietud que caracterizan los barrios residenciales - lo cual es también señalado por Badía- además de ser un lugar lleno de colorido. Así lo percibe también, más de cuarenta años después, el joven Flaubert:

Toute la vie de Damas est concentrée dans les bazars, ils sont aussi animés et grouillants de monde que les rues son désertes et silencieuses; les robes des hommes, roses, vertes ou bleues et la quantité de soieries, le tout éclairé par le jour doux d'en haut, fait de l'ensemble une grande couleur bigarrée d'un charme singulier. (Flaubert 1974: 590)

Sin embargo, la creciente presencia de capital occidental en la ciudad influirá de manera más rotunda que en otros casos en la configuración futura de los bazares y de lo que en ellos se puede encontrar. De una manera mordaz comenta Colin Thubron los efectos que los medios de transporte y la libre circulación de mercancías han provocado en los bazares:

Más al norte, el bazar llega a los muros de la Gran Mezquita. [...] Aquí se ensancha y cobra altura el Suq Hamidié, centro comercial de moda de Damasco. Bajo el claroscuro que proyectan las rejas del tejado se venden productos occidentales, telas sirias y toda clase de baratijas de regusto oriental, que son todo un comentario sobre el gusto de los turistas: farolillos pintados, dagas de plata, esterillas de oración de fabricación industrial sobre trama de algodón... (Thubron 2002: 236)

Ya a finales del siglo XX los productos artesanales y las mercancías exóticas dan paso a los souvenirs, pequeños recuerdos a bajo precio, fabricados en cualquier parte del mundo, cuya única cualidad indispensable en el caso de Damasco, una vez más, es la de parecer orientales.

Continúa posteriormente: "El Suq Hamidié posee una especie de prisa que el resto de los bazares desprecia. Quizá se deba al efecto del comercio turístico, pues los damascenos dicen que la prisa está escrita en los cascos del asno" (Thubron 2002: 237). Este zoco, situado al oeste de la mezquita, está inserto en una antigua columnata romana recientemente despejada. Fue erigido en 1780 y reconstruido en 1863 -la misma fecha de la apertura de la carretera que une Damasco con Beirut- por orden del sultán Abdul Hamid II, quien le otorga su nombre. En su interior, las tiendas se abren a los lados en las altas paredes, y está rematado con una cubierta de bóveda de cañón en hierro. Otro zoco cubierto es el Suq Midhat 
Pasha, ubicado en el extremo occidental de la Vía Recta, que está especializado en vestimentas masculinas tradicionales.

Sin embargo siempre permanece un comercio local que parece insustituible: "La integridad de los bazares se mantiene gracias a las calles más humildes, en el honrado cuero y en las guarnicionerías del Suq al-Surujiye, donde los beduinos compran cuerda y bridas y luego van al mercado de fruta y verdura del otro lado de los muros" (Thubron 2002: 237).

Rosa Regás testimonia una ciudad mucho más animada, en la que la vida ya no gira solamente en torno al bazar, aunque el movimiento y la agitación seguirán en una órbita conceptual similar, en torno al concepto de mercadería.

Lo más espectacular de Damasco es la vida de la calle. Cualquier tipo con unas uvas se constituye en mercado y agrupa a su alrededor en un instante a otro que extiende sobre un trapo sus destornilladores, postales o camisetas, y a multitud de personas que comienzan a indagar precios, a regatear y a comprar: frutas, verduras, helados, zumos, revistas antiguas, cepillos de dientes o antigüedades, cualquier cosa sirve para ponerse a vender, esa facultad que los damascenos llevan en la masa de la sangre. (Regás 2003: 30)

Será el mercado, el zoco árabe, el pulso de la vida pública en la ciudad. En la ciudad antigua, visitará el zoco Hamidie, del que nos dirá lo siguiente:

El zoco Al Hamidie es sin duda uno de los más hermosos del mundo. Una larga galería pavimentada y ancha, con una cubierta de hierro en forma de cúpula, que el tiempo y la intemperie han ido desgastando, jalonada de minúsculos agujeros que se convierten en pequeños puntos de luz, como un lejano cielo estrellado en pleno día. Las tiendas se suceden a ambos lados, repletos los escaparates con ese sentido de la acumulación que sólo se encuentra en un mundo de mercaderes. Por la calzada avanzan apretujados en ambas direcciones hacia sus quehaceres los aguadores con sus antiguos y complicados depósitos de latón como insólitos instrumentos musicales repletos del agua que ofrecen en vasos por unas monedas a los sedientos [...]. En este zoco, tan distinto de otros zocos de la ciudad antigua, como el de las telas, el zoco Al Zurie de especias, condimentos y pastelería, el zoco Al Salie de frutas y legumbres, se pueden encontrar joyas y bisutería, sedas y alfombras, utensilios de cobre, latón y artesanía en general, dispuesto gran parte de ello esperando la llegada en verano de los clientes extranjeros que poco a poco van desplazándose de los peligrosos Egipto y Argelia en busca de lugares exóticos que ellos mismos diluirán y desharán como se deshace en la mano el hielo bajo el sol. (Regás 2003: 47-48) 
Una vez más hace notar las diferencias entre lo que podrían ser espacios transformados por el turismo y aquéllos que mantienen intacta su fisonomía local. Por fortuna, los zocos damascenos preservan en general su aspecto y carácter tradicional, por lo que sin duda serán uno de los lugares preferidos por la autora.

La ciudad antigua está amurallada y contiene la mayor parte de los monumentos y maravillas que el turista quiere ver. Pero Damasco no ha llegado aún a los extremos de Marrakesh o El Cairo, y los zocos siguen siendo un verdadero mercado donde compran los ciudadanos y los que vienen del extrarradio o de las afueras. Es fácil pasearse por sus callejas y exceptuando a la entrada de Al Hamidie [el zoco] apenas nadie persigue a los extranjeros. (Regás 2003: 47)

\subsection{Los baños}

Los baños públicos de la ciudad musulmana, o hammams, son en primer lugar la consecuencia de los preceptos litúrgicos de pureza y ablución del Islam. Pero para el ciudadano, su función va más allá y se extiende a lugar de recreación, como espacio para conversar o descansar. Se localizan en la medina, en las inmediaciones de la mezquita y el Suq, pero más cerca de los barrios residenciales.

Los bazares comprenden asimismo baños de magnífica apariencia; el primer salón es espacioso y con luz de grandes ventanas que dan a la calle; remata en una hermosa cúpula de madera, adornada de arabescos. Alrededor del salón corre una galería elevada, y en ella dispuestos varios colchones, sobre los cuales van a sentarse las personas que salen del baño, gravemente envueltas en toallas; formando un espectáculo algo divertido. Hay de ordinario en medio del salón una fuente de mármol, y a cierta altura hay tendidas algunas cuerdas para poner toallas a secar. (Ali-Bey 1982: 437)

Ya a mediados del siglo XX Thubron nos cuenta mucho más sobre los baños públicos en Damasco. Cuando la visitó había todavía cuarenta y uno abiertos en la ciudad, entre los cuales nos describe el Hammán al-Yosé, el segundo más antiguo de la ciudad, construido poco después de los tiempos de Saladino:

Su sobriedad medieval ha degenerado en lo rococó: una sobrecarga de arañas de luces y un mural al estilo de Estambul. En la sala principal, a ambos lados, sobre una tarima vallada con divanes, había una benigna fila de hombres en albornoz fumando en pipa y tomando café. Un sudanés me dobló la ropa, me envolvió en toallas y me colocó un turbante [...]. Me hicieron pasar por una puerta baja y cruzar una serie de estancias de vapor cada vez más calientes y densas. El suelo que pisaba tenía la suavidad del aceite y era de color gris y rojo apagado. Corría agua sobre los azulejos por unos canales, pero con muy poca fuerza, y una luz verdosa se proyectaba desde los 
orificios acristalados de la cúpula de la chauderie [...]. Cuando llegué a la sala más caliente, me atrapó un turco muy musculoso y me llenó de jabón. Me lavó y me restregó con un guante de pelo de camello y me roció con agua muy caliente. [...] Al dar la vuelta a la esquina, el vapor levanta el sitio y el ruido de las qabqbs desaparece. El mundo natural dibuja sus contornos por fin: un elíseo maravillosamente sucio. (Thubron 2002: 245)

Especialmente creíble, como en muchos aspectos, resulta el testimonio de Rosa Regás respecto a los baños, además de la importancia que adquiere por ser ésta una situación de privacidad en la que raramente es mostrada la mujer islámica.

Las mujeres están distendidas, entre ellas ya no tienen que cubrirse, y me dice Teresa que sus conversaciones son tan libres e incluso a veces tan procaces, que ríen a carcajadas sin temor ni pudor y nadie diría que son las mismas que caminan por la calle con los ojos bajos y la cabeza cubierta. Ahora, sólo con bragas o desnudas, van echándose cuencos de agua y cuando la piel se reblandece ya está dispuesta para el masaje. [...] Una vieja beduina con la cara tatuada, el pelo mal recogido en un moño del que se escapan guedejas mojadas, con un lienzo negro chorreando atado a la cintura y los pechos colgando vacíos, rasca espaldas y piernas con un guante de crin hasta arrancar las escamas muertas y dejar la piel roja pero lisa y suave como la seda. Nosotras compartimos la pileta con una mujer damascena que trabajaba en una empresa extranjera y llevaba biquini porque su pudor ya era occidental [...]. (Regás 2003: 91-92)

\subsection{El Vergel del Edén}

Damasco debe ciertamente su existencia y su fascinación a las aguas del río Barada, que han dado vida al fertilísimo oasis del cual surge la ciudad, el cual permite entre otros la existencia de suntuosas huertas y jardines. Según Domingo Badía, a principios del siglo XIX la tierra era tan fértil que sus habitantes no recuerdan ni un año de carestía (1982: 441). Tanto él como el resto de viajeros enviados con alguna misión oficial harán una descripción del jardín que se caracterizará por la enumeración de árboles frutales, flores y plantas, buscando un parecido occidental en caso de ser necesario, pero en todo caso enfocada a dar cuenta de los recursos de los que dispone la ciudad: naranjos, limones, albaricoques, ciruelos, albérchigos, higueras, cedros, sicomoros, rosas damascenas, son sólo algunos de los ejemplos que más aparecen.

La sublimación de la naturaleza y la vegetación que invaden el oasis vendrá por supuesto de mano de los escritores románticos, 
como Lamartine, cuya descripción del vergel nos recuerda en éste, como en otros aspectos, a las idealizaciones miliunanochescas ${ }^{5}$.

Le regard tombait d'abord sur la ville qui, entourée de ses remparts de marbre jaune et noir, flanquée de ses innombrables tour carrées de distance en distance, couronnée de ses créneaux sculptes, dominée par sa forêt de minarets de toutes formes, sillonnée par les sept branches de son fleuve et ses ruisseaux sans nombre, s'étendait à perte de vue dans un labyrinthe de jardins en fleurs, jetait ses bras immenses, ça et là, dans la vaste plaine par-tout ombragée, par-tout pressée par la forêt de dix lieues de tour de ses abricotiers, de ses sycomores, de ses arbres de toutes formes et de toute verdure; semblait se perdre de temps en temps sous la voûte de ses arbres, puis reparaissait plus loin en larges lacs de maisons, de faubourgs, de villages; labyrinthe de jardins, de vergers, de palais, de ruisseaux, où I'œil se perdait et ne quittait un enchantement que pour en retrouver un autres; nous ne marchions plus [...] (Lamartine 1843: 63)

El recinto amurallado, copado de vegetación de exuberante variedad y belleza y atravesado por un río, remite a las descripciones del Paraíso Terrenal, y esta será la imagen más recurrente desde que, según cuenta la leyenda, Mahoma dijera que no quería entrar a Damasco porque sólo se puede ir a un paraíso. Tal y como nos cuenta Thubron, "los damascenos son los únicos que aran y riegan su Edén, viven y mueren en él y continúan relacionándolo con el paraíso" (2002: 23). George Robinson encuentra perfectamente comprensible el empleo de esta comparación: "well may the enthusiastic Arab be excused when he applies to it the more exaggerated epithet of 'Eden' or 'Terrestrial Paradise'"' (1837: 134).

Esta no será la única óptica posible en el romanticismo, pues si en Lamartine el paisaje adquiere un carácter metafísico, también existirán las descripciones románticas de índole más sentimental, como es el caso de Adolfo de Mentaberry (Martín Asuero 2004: 100): "pues estas naturalezas sensuales y contemplativas, de rica imaginación y pobre sentido, son felices cuando tienen como ellos dicen, algo de agua, algún perfume grato, algún objeto bello que embelese sus ojos y alguna música próxima o lejana que recree su oído" (Martín Asuero 2004: 102). Al mismo tiempo que Mentaberry, quien estuvo en la ciudad en 1873, vuelven a proliferar las

5 "El huerto ofrecía toda clase de frutos: damascos, cerezas y uvas capaces de sanar a los enfermos de sus males [...]; había higos de esos que inspiraron a los poetas..., negros como las ardientes hijas de Abisinia, y peras de Sinaí, de Alepo y Grecia, y granadas como pechos turgentes de adolescentes. Y almendras que el poeta compara con tímidas vírgenes envueltas en mantos de nácar [...] flores y plantas de alheña, de pimienta, rosas... Un jardín como no había otro, lleno de prodigios como si se tratara del mismísimo jardín del Edén". (Anónimo 2006: 276277) 
descripciones del jardín en las que el lirismo ha perdido gran parte de su importancia a favor de una descripción basada principalmente en la identificación de los elementos que lo componen: esta es la perspectiva de Rivadeneyra o de Narciso Pérez Reoyo. También del ámbito hispánico, el peculiar caso de Arosemena, quien nos daba la peor de las imágenes de la ciudad, merece ser mencionado porque nos sitúa en la convergencia de un nacionalismo, o más ampliamente, de un culturalismo, con una representación del exotismo como visión exaltada de los espacios ajenos; la ciudad, como representación cultural, será la que sufra esa mirada que la minusvalora, mientras que la naturaleza será objeto de alabanzas: "Esta poblacion de Damasco, grande pero miserable, se halla situada en un fértil i delicioso valle que produce las mas delicadas frutas. Jamas habia comido en los paises mas meridionales de Europa uvas tan excelentes como las que se recojen en los jardines i huertas del pais" (Arosemena 1859: 57).

Con el siglo XX esa imagen se irá poco a poco deteriorando, y cuando sea visitada por Rosa Regás, la mayor parte del jardín habrá cedido terreno ante el progreso.

Damasco la reina del agua, dicen las guías, la de las tierras fértiles, la de los cielos benignos. Como una esmeralda verde en medio de un desierto de arenas doradas se abre al este de la cordillera del Antilíbano que de norte a sur corre paralela al mar. La esmeralda es su oasis que a pesar de haber sido invadido sin miramientos por la ciudad y el desarrollo indiscriminado, todavía conserva, antes de convertirse abruptamente en desierto, huertas y riberas frondosas, campos de violetas, rosas damascenas y mimosas, sembrados y labrantíos, extensiones de frutales, higueras y olivos, y caminos bordeados de nogales, un paraíso ya descrito por Alí Bei al Abbasi hace casi doscientos años. (Regás 2003: 63)

Es entonces cuando la hipérbole del paraíso adquiere el cariz de un simulacro, tópico relegado a servir únicamente como postal de agencia de viajes, pues la ciudad contemporánea es anti-exótica por definición:

Los grandes nogales que bordeaban los caminos se han cortado y se ha vendido la madera y los caminos se han transformado en autovías - autopistas por las que discurren cientos de autobuses y coches, perdido para siempre el equilibrio entre Damasco y el oasis, la reserva de hortalizas, frutos y árboles que protege la ciudad del desierto. Enloquecidos los sucesivos regímenes, como los de nuestros países, por dar a los campesinos una estructura de vida urbana que para ellos no significa más que una forma de vivir que no comprenden y unos usos a los que no están hechos, subestimaron el problema y ahora la fetidez de los canales muestra la insuficiencia de 
las aguas para la ciudad y el oasis que la rodea. (Regás 2003: 6364)

\section{Conclusión}

Como ya advertíamos en nuestra introducción, viajar es abrir nuevos horizontes, descubrir al otro, y en él verse a uno mismo. La primera idea que se desprende de esta panorámica de los viajeros que visitaron Damasco es que las metamorfosis en el relato de viajes vienen determinadas más bien por los cambios acaecidos en el sistema cultural en el que se inserta el autor en cuestión, que a causa de las transformaciones sufridas por la urbe misma. Estos cambios, ya sean de índole temática o estética, dan lugar a multitud de discursos diferentes sobre la ciudad que hasta pueden llegar a resultar contradictorios, y sin embargo todos ellos son caras del poliedro que es la imagen real y literaria de la ciudad. También observamos que en muchas ocasiones las modificaciones que tienen lugar en el seno de ésta, especialmente con la llegada de la modernidad, conviven en el relato con los tópicos que presentábamos al inicio, imágenes idílicas ya casi diluidas en las estructuras propias de la vida contemporánea. No será ajeno en este caso tampoco el anhelo del viajero, aquel que tras la transformación de su relación con el lugar visitado, como sabemos, siguiendo la lógica cultural de la sociedad de masas, hasta convertirse en turista, "criatura romántica pasada por el fenómeno de las masas" (Tollinchi 1989: 300),el cual no dejará sin embargo de reclamar su imagen exótica de la urbe, hecho que nos recuerda aquella idea romántica expuesta anteriormente por la que la ciudad literaria se revelaba en función del deseo del autor.

Desde la muerte del viaje descrita por Levi-Strauss ${ }^{6}$, que ratificaba la imposibilidad de un auténtico acercamiento al otro, el modelo imagológico damasceno deviene un viaje al paraíso perdido, un destino más del "viaje imposible", el fenómeno del turista contemporáneo según el antropólogo francés Marc Augé, quien sitúa las nuevas fronteras del conocimiento de la otredad:

\footnotetext{
6 "Viajes: cofres mágicos de promesas soñadoras, ya no entregaréis vuestros tesoros intactos. Una civilización proliferante y sobreexcitada trastorna para siempre el silencio de los mares. [...] Entonces comprendo la pasión, la locura, el engaño de los relatos de viaje. Traen la ilusión de lo que ya no existe y que debería existir aún para que pudiéramos escapar a la agobiadora evidencia de que ha sido juzgado 20000 años de historia. Ya no hay nada que hacer: la civilización no es más esa flor frágil que preservábamos, que hacíamos crecer con gran cuidado en algunos rincones abrigados de un terruño rico en especies rústicas, sin duda amenazadoras por su lozanía, pero que permitían variar y vigorizar el plantel. La humanidad se instala en el monocultivo; se dispone a producir la civilización en masa, como la remolacha. Su comida diaria sólo se compondrá de este plato". (Levi-Strauss 1988: 42)
} 
El viaje imposible es ese viaje que ya nunca haremos más. Ese viaje que habría podido hacernos descubrir nuevos paisajes y nuevos hombres, que habría podido abrirnos el espacio de nuevos encuentros. Eso ocurrió alguna vez y algunos europeos sin duda experimentaron entonces fugitivamente lo que nosotros experimentaríamos hoy si una señal indiscutible nos probara la existencia, en alguna parte del espacio, de seres vivos capaces de comunicarse con nosotros. Pero, mientras esperamos ese improbable o remoto encuentro, ya nuestra ciencia ficción le presta los colores de la guerra. (Augé 1998:16)

\section{Bibliografía}

ALI-BEY (1982): Viajes por Arabia, Palestina, Siria y Turquía. Barcelona: Olañeta.

ALMARCEGUI, Patricia (2007): Ali-Bey y los viajeros europeos a Oriente. Barcelona: Bellaterra.

- (2004): "La metamorfosis del viajero a Oriente". Revista de Occidente, núm. 240, pp. 105-117.

AMRAM, Rica (2007): "El Libro de viajes de Benjamín de Tudela: del mito a la realidad histórico-geográfica". CEHM, num. 30, pp. 13-24.

ANÓNIMO (2006): Las mil y una noches. Buenos Aires: Colihue.

AROSEMENA, Domingo (1859): Sensaciones en Oriente o Ympresiones bíblicas de un granadino en Tierra Santa. Nueva York: Robert Craighead.

AUGÉ, Marc (1998): El viaje imposible. El turismo y sus imágenes. Barcelona: Gedisa.

- (1996): El sentido de los otros. Barcelona: Paidós.

BALARD, Michel (1988): "L'Orient: concept et images dans l'occident médiéval", en L'Orient: concept et images. XVe Colloque de I'Institut de Recherches sur les Civilisations de l'Occident Moderne. Paris: Université de Paris IV- Sorbonne.

BENEVOLO, Leonardo (1995): Histoire de la ville. Marseille: Parenthèses.

BRUNEL, Pierre (1886): "Préface", en François Moureau (ed.), Métamorphoses du récit de voyage: Actes du Colloque de la Sorbonne et du Sénat (2 mars 1985). Genève: Slatkine.

BURCKHARDT, Johann Ludwig (1822): Travels in Syria and the Holy Land. London: John Murray.

FLAUBERT, Gustave (1974): Par les champs et par les grèves; Voyages et carnets de voyages. Fuvres complètes, tome 10. Paris: Club de I'Honnête Homme.

FRESCOBALDI, Lionardo di Niccolò (1818): Viaggio di Lionardo di Niccolò Frescobaldi in Egito e in Terra Santa. Roma: Carlo Mordacchini.

GUERRERO, Francisco (1593): El viaje de Hiervsalem que hizo Francisco Guerrero. Valencia: Hered. de Ioa Navarro.

GONZÁlEZ ALCANTUD, José Antonio (1989): El exotismo en las vanguardias artísticas. Barcelona: Anthropos.

- (1988): "Teoría del exotismo" [en línea]. Gazeta de Antropología, núm. 6, artículo 2. En:

http://www.ugr.es/ pwlac/G06 02JoseAntonio Gonzalez Alcantud.html [Consulta: abril de 2011]. 
GRAÇA, Luis (1983): A visao do oriente na literatura portuguesa de viagens: os viajantes portugueses e os itinerários terrestres (15601670). Lisboa: Imp. Nac. Casa da Moneda.

LAMARTINE, Alphonse (1843): Voyage en Orient 1832-1833. Deuxieme partie. Paris: Charles Gosselin.

LEVI-STRAUSS, Claude (1988): Tristes Trópicos. Barcelona: Paidós Ibérica.

LITVAK, Lily (2004): "Topografía de la otredad. Estrategias de la escritura en las crónicas de viaje del siglo XIX". Revista de Occidente, núm. 240, pp. 92-104.

- (1986): El sendero del tigre: Exotismo en la literatura española de finales del siglo XIX (1880-1913). Madrid: Taurus.

LOTI, Pierre (2008): La Galilée. Paris: Payot.

MANDEVILLE, John (1839): The voiage and travile of John Maundevile. London: Edward Lumley.

MARTÍN ASUERO, Pablo (2004): Descripción del Damasco Otomano (18071920) según las crónicas de viajeros españoles e hispanoamericanos. Madrid: Miraguano.

MORALES OSORIO, Susana; y FERNÁNDEZ HOYOS, Sonia (2006): "El mediterráneo a través de la ficción: el extraño caso de Sir John Mandeville". Anuario de Estudios Medievales 36/1, enero-junio de 2006, pp. 335-354.

MORATÓ, Cristina (2006): Las damas de oriente: grandes viajeras por los países árabes. Barcelona: Debolsillo.

POCKOCKE, Richard (1772): Voyage en Oriente. Paris: J. P. Costard.

POPEANGA, Eugenia (coord.) (2010): Ciudad en obras. Metáforas de 10 urbano. Bern: Peter Lang.

REGÁS, Rosa (2003): Viaje a la luz del Cham: Damasco, El Cham, un pedazo de tierra en el paraíso. Madrid: Siete Leguas.

RIVADENEYRA, Adolfo (2006): Viaje de Ceilán a Damasco. Madrid: Miraguano.

ROBINSON, George (1837): Travels in Palestine and Syria, vol. 2. London: Henry Colburn.

SEGALEN, Victor (1999): Essai sur l'exotisme. Paris: LGF.

SORIANO NIETO, Nieves (2009): Viajeros románticos en Oriente: Delacroix, Flaubert, Nerval. Murcia: Universidad de Murcia.

SOURIAU, Etienne (1998): Diccionario Akal de estética. Madrid: Akal.

STANHOPE, Lady Hester (1846): Travels of Lady Hester Stanhope. London: Henry Colburn.

SCHILBERGER, Johann (1966): Bondage and travels of Johann Schilberger. New York: Burt Franklin.

THÉVENOT, Monsieur de (1674): Suite de voyage en levant. Seconde partie. París: Charles Angot.

THUBRON, Colin (2002): Entre árabes: Semblanza de Damasco; Las montañas de Adonis. Barcelona: Península.

TODOROV, Tzvetan (1991): Nosotros y los otros: ensayo sobre la diversidad humana. México: Siglo XXI.

TOLLINCHI, Esteban (1989): Romanticismo y modernidad. Ideas fundamentales de la cultura del siglo XIX. San Juan: Universidad de Puerto Rico. 
TORRE, Guillermo de (2001): Literaturas europeas de vanguardia. Sevilla: Renacimiento.

TUDELA, Benjamín de (1982): Libro de viajes de Benjamín Tudela. Barcelona: Riopiedras.

VARTHEMA, Ludovico di (2004): Le voyage de Lodovico di Varthema en Arabie \& aux Indes orientales (1503-1508). París: Chandeigne.

YOUSSEF, Aida (1993): Cultura, espacio y organización urbana en la ciudad islámica. Madrid: Instituto Juan de Herrera. 